\title{
THE EVOLUTION OF NATURAL DIAMOND GROWTH CONDITIONS.
}

\author{
G.P. Bulanova and L.A. Pavlova.
}

Yakutsk Institute of Geosciences, Siberian Branch, Academy of Sciences, Yakutsk, USSR.

A comprehensive study of whole dlamonds from three Yakutian kimberlite pipes as well as plane-parallel plates cut out of them was carried out. From birefringence (BF), and phfotoluminescence (PL) patterns, the internal stratigraphy and change in luminescence colour were studied and the location of syngenetic inclusions in growth zones and areas was determined. The composition of inclusions were determined using the electron microprobe.

The purpose of the present study was to trace the evolution of growth conditions of natural diamond monocrystals from Yakutian kimberlite pipes.

octahedral monocrystals show an inhomogeneous structure and a complicated growth history. Study of diamond anatomy by BR-patterns has established their growth characteristicsi fine zoning. zoned-sectorial structure, dislocations the presence of seeds, and the distribution of macro- and micro-inclusions. PL-patterns give a more general idea of the growth history of the crystals: change in growth morphology, alternation of physlcally homogeneous areas in various stones. Three heterogeneous areas that reflect the main trend of their growth history: central (yellow-luminescent)

intermediate (blue-luminescent) $\rightarrow$ peripheral (no luminescence) (Beskrovanov, 1986) are the most widespread in diamonds from the Mir pipe (ca. twothirds). Such crystals also exhlolt a change in growth morphology: cube, cubo-octahedron or rounded form $\rightarrow$ coarse layered octahedron $\rightarrow$ fine layered octahedron. Such diamonds constitute only one-third at Udachnaya and 23d Party Congress ploes. The greater part of octahedral diamond experience no change of growth form.

The zoned-sectorial distribution of syngenetic inclusions in diamonds was studied.For inclusions of the ultrabasic paragenesis,the following crystallization sequence of silicates was found: $01 \leftarrow$ Ol+GrtEnst $\leftarrow$ Ol+GrtEnst+CPX. This is similar to the crystallization sequence of silicates from ultrabasic melt (Mysen. Kushiro. 1977).suggesting that diamonds containing ultrabasic inclusions grew from carbon solution in a silicate melt (fluid). 
A change in composition was found fom chromite and olivine inclusions located in different zones in the same diamond crystal. For chromites, this change can be expressed as $\mathrm{MgAl} \leftarrow \mathrm{FeCr}$ or $\mathrm{Mg}$, Fe - Fe(Cr, AL). For diamond inclusion olivines, normal and inverse zoning is observed. This indlcates different sources for mantle rocks from which the olivines and chromites were entrapped in diamonds.

Diamonds with the eclogitic sulte of inclusions are similar in internal structure to dlamonds with the ultrabasic inclusion suite This indicates that they also grew in a liquid. A change in composition is shown by omphacites and pyrope-almandines from different growth zones in the same diamond. Coexisting palrs of these minerals become somewhat richer in $\mathrm{Mg}$ and $\mathrm{Fe}$ from central zone to peripheral.

"Coated" dlamonds, which exemplify coarse zoning, were found to belong to the eclogitic paragenesis. Besides pyrope-almandine. omphacite. coesite and rutile, typical for this paragenesis, they also contain sanidine, biotite, apatite and micro-inclusions compositionally similar to melt inclusions.The same kinds of microinclusions were found by Naivon et. al. (1989). It appears that coated diamond forms at the final, subsolidus evolutionary stage of cologite melts, whereas the coat itself forms from a fluld phase. Probably this fluid predated the appearance of kimberlite melt.

The results of the present study lead to several important conclusions about the growth history of natural diamond. Changes in the composition of mineral inclusions located in different srowth zones of the same octahedral diamond are smooth and small, and are probably due to liquid (fluid) differentiation during the diamond Erowth. The temperature range of single diamond crystallization is 50 to $200^{\circ} \mathrm{C}$, the fOz value can vary from IW buffer to $W M$.

Different types of mantle rocks of ultrabasic and basic composition, formed in Archean time in the regions of stable cratons, are the sources of diamonds in kimberlite rocks. It appears that diamonds from each different source are characterized by their own evolution path. 